\title{
The Contemplation of the Development of a Disaster Care Model for the Elderly
}

\author{
Maryam Chehrehgosha ${ }^{1,2 *}$
}

1. Department of Geriatrics, University of Social Welfare and Rehabilitation Sciences, Tehran, Iran

2. Laboratory Sciences Research Center, Golestan University of Medical Sciences, Gorgan, Iran.

\section{Article Type:}

Letter to Editor

\section{Article History:}

Received: 19 Jan 2020

Revised: 5 Feb 2020

Accepted: 29 Feb 2020

*Correspondence:

Maryam Chehrehgosha,

Department of Geriatrics, University of Social Welfare and Rehabilitation Sciences, Tehran, Iran.

Chehrehgosha2008@gmail.com

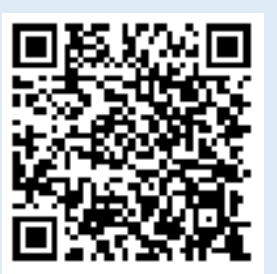

DOI: 10.29252/jorjanibiomedj.8.1.1

\begin{abstract}
The COVID-19 crisis has changed the world and many aspects of our lives, even the way we treat the elderly. Evidently, the pandemic has put tremendous pressure on the healthcare system of every country, and there have been insufficient healthcare resources for the affected patients. We should seek to develop more care models for the elderly, so that when all human services are stopped.
\end{abstract}

Keywords: Disaster, Care model, Elderly, COVID-19

\section{Statement}

The COVID-19 crisis has changed the world and many aspects of our lives, even the way we treat the elderly. In addition, the COVID19 pandemic has urged us to face the phenomenon of ageism, and our response to the pandemic is a testament to generational discrimination (1). Evidently, the pandemic has put tremendous pressure on the healthcare system of every country, and there have been insufficient healthcare resources for the affected patients. Under such circumstances,

Copyright@ 2018, Jorjani Biomedicine Journal has published this work as an open access article under the terms of the Creative Commons Attribution License (http://creativecommons.org/licenses/by-nc/4.0/) which permits noncommercial uses of the work while it is properly cited. 
ethical decisions should be made on a daily basis by the healthcare systems of all countries. An important question to address in this regard is the prioritization of the patients for receiving care. In such a competition, the elderly might stand a slim chance (2).

The presence of comorbidities and chronic health conditions render the elderly a vulnerable population in the acute phase of a pandemic due to the lack of adequate medication and health resources, even if they do not contract the disease during the pandemic (3). During the lockdown necessitated by the pandemic, the elderly who are alone or complex patients have difficulty in preparing food, drugs, and other supplies. Social distancing has also hindered the possibility of providing social care services during this period by formal or informal caregivers and social workers (4). The elderly were not born in the digital age and are reluctant to use the technology, which leads to their inability to communicate with their loved ones during the quarantine period (5). Consequently, they are isolated at home and are more prone to anxiety, depression, and loneliness.

Various models of care have been developed for the provision of care to the elderly in different situations, such as transitional care, acute hospital care, nursing home care, community-based, long-term services and support, and home care (6). However, it remains unclear which of these models has helped the elderly while there is the lack of sufficient healthcare resources and services and formal and informal care, social isolation, and ageism in the COVID-19 crisis.

Numerous casualties have been reported among the elderly in the countries with ageing populations (7). Unfortunately, we have not succeeded in care provision during the acute phase of the pandemic to the elderly, as well as in the provision of community-based care services and web-based infrastructures of care, especially in developing countries. This chronic disease has been a disaster to the elderly rather than a pandemic. It seems that with the lesson we have learned from this disaster, we should seek to develop more care models for the elderly, so that when all human services are stopped, we could save the lives of more senior citizens and provide more care and services to this population. 


\section{References}

1. Ayalon L, Chasteen A, Diehl M, Levy BR, Neupert SD, Rothermund K, et al. Aging in Times of the COVID-19 Pandemic: Avoiding Ageism and Fostering Intergenerational Solidarity. Journals Gerontol Ser B [Internet]. 2020 Apr 16; Available from: [DOI:10.1093/geronb/gbaa051]

2. Swiss Academy Of Medical Sciences. COVID19 pandemic: triage for intensive-care treatment under resource scarcity. Swiss Med Wkly [Internet]. 2020 Mar 23 [cited 2020 Jun 30];150:w20229. Available from: https://pubmed.ncbi.nlm.nih.gov/32208495/

[DOI:10.4414/smw.2020.20229]

3. Wakui T, Agree EM, Saito T, Kai I. Disaster Preparedness among Older Japanese Adults with Long-Term Care Needs and Their Family Caregivers. Disaster Med Public Health Prep [Internet]. 2017 Feb 1 [cited 2020 Jun 30];11(1):31-8. Available from: https://pubmed.ncbi.nlm.nih.gov/27460161/

\section{[DOI:10.1017/dmp.2016.53]}

4. Petretto DR, Pili R. Ageing and COVID-19: What is the role for elderly people? [Internet]. Vol. 5, Geriatrics (Switzerland). MDPI Multidisciplinary Digital Publishing Institute; 2020 [cited 2020 Jun 30]. Available from:https://pubmed.ncbi.nlm.nih.gov/32357582/ [DOI:10.3390/geriatrics5020025]

5. Armitage R, Nellums LB. COVID-19 and the consequences of isolating the elderly [Internet]. Vol. 5, The Lancet Public Health. Elsevier Ltd; 2020 [cited 2020 Jun 30]. p. e256. Available from:

https://www.ncbi.nlm.nih.gov/pmc/articles/PMC7 104160/ [DOI:10.1016/S2468-2667(20)30061-X]

6. Hazzard's Geriatric Medicine and Gerontology, Seventh Edition - Kindle edition by Jeffrey B. Halter, Joseph G. Ouslander, Stephanie Studenski, Kevin P. High, Sanjay Asthana, Nancy Woolard, Christine S. Ritchie, Mark A. Supiano. Professional \& Technical Kindle eBooks @ Amazon.com. [Internet]. [cited 2020 Feb 12]. Available from: https://www.amazon.com/Hazzards-GeriatricMedicine-Gerontology-7Eebook/dp/B01M18PVZ0

7. Walker P, Whittaker C, Watson O, Baguelin M, Ainslie K, Bhatia S, et al. Report 12: The Global Impact of COVID-19 and Strategies for Mitigation and Suppression. 2020.

\section{How to cite:}

Chehrehgosha M. The Contemplation of the Development of a Disaster Care Model for the Elderly. Jorjani Biomedicine Journal. 2020; 8(1): 1-3. 